\title{
User participation in housing regeneration projects
}

\author{
H. Sadıkoğlu ${ }^{1} \&$ A. Özsoy ${ }^{2}$ \\ ${ }^{1}$ Faculty of Architecture and Design, Bahcesehir University, Turkey \\ ${ }^{2}$ Faculty of Architecture, Istanbul Technical University, Turkey
}

\begin{abstract}
The quality of existing residential buildings is one of the biggest problems today. There are a number of different approaches to improve the quality of existing housing stock with user participation. Regeneration policies for the existing housing stock can create opportunities for improving spatial standards, and can preserve the social-cultural and economic value of the stock. Europe is rich in terms of housing estates that were designed based on modernist ideas after the World Wars as a means of solving housing problems. European countries have developed policies for improving the quality of those neighbourhoods. Nowadays, most regeneration policies focus on design, construction methods materials and financial resources, but they should also focus on user participation issues. The methodology of this research is built on examining the approaches and implementations related to the participation in housing regeneration projects in European countries and Turkey. The kind of policies and implementations related to user participation that exist in Europe and how such participation is organized in the projects has been examined. The research consists of a literature review on European regeneration projects, plus a survey and in-depth interviews on a modern housing settlement in Turkey to discuss the potential of user participation. A research case study was conducted on a modern housing project, in the Levent District, which was built in the 1950s. Questionnaires and in-depth interviews were employed to understand the users' attitudes to a regeneration project. As part of studying the process of the selected projects, the participation type will be analysed in order to underline the importance of user participation on regeneration projects, and user participation potential will be discussed.

Keywords: housing regeneration, quality of space, user participation and existing housing stock.
\end{abstract}




\section{Introduction}

A large part of the existing housing stock consists of residential buildings that have a long life span. During this time, they are in a relationship with their users, and are affected by them. Users are very important actors in design and construction processes. As main decision makers, they have responsibilities and the quality of space is related to the users' demands. Users have the potential to improve the design and construction quality. It is important that the demands should be correct and conscious.

Today's problematic subject concerns the existing housing stock and its spatial quality problems. In Europe, there are some regeneration projects that have been built to high standards by participatory organisations. So, user participation affected the process not only in terms of new construction, but also in existing stock regenerations. The organisations focused on existing buildings' quality problems and forming solutions with sustainable development programs; strategies and policies were developed with the aim of spatial, social, cultural and economic sustainability [1]. Sustainable development in the cities can be provided with public participation [2].

Existing housing stock is an important source for sustainable development approach. In Europe, modern architectural stock built between 1930 and 1970 is very important for a nation's cultural, social, ecological and economic sustainability. In recent years, these buildings have various spatial quality problems that harm the integrity of their social, cultural, ecologic and economic sustainability, although they have some potential for solving spatial quality problems. Nowadays, new strategies are developed for regenerating buildings to improve quality of space. While some regeneration projects are done with the help of user participation and a great organisation, others are solved based on users' own initiatives. It is necessary to develop a housing regeneration strategy with the participation of the users.

The aim of this study is to understand the participation tendencies and behaviours of the users in housing regeneration approaches in Turkey. The thesis of the study is that there are some factors which are important to develop a participative housing regeneration strategy. These factors are directly related with the users' characteristics, specialities and their ideas. The type of the participative organisation can be defined with the users and their behaviours.

In this research, user participation tools and strategies are examined and the results of the in-depth interviews and questionnaire on a modern housing settlement, in Levent District, which was built in 1954, are analysed. User participation tendencies and their importance to the regeneration strategies of modern housing settlements and quality improvement organisations are researched through this analysis. It is our contention that historically significant housing estates can be protected and regenerated with user participation. With this study, it is aimed to define the relationship between users' characteristics, behaviours and their tendencies on participative regeneration.

The method of this study includes a literature review, in-depth interviews and a questionnaire (with users) analysis. Firstly, a historical literature review was 
carried out on modern housing stock in Europe and Turkey, followed by an examination of housing regeneration approaches and user participation tendencies in European countries. After learning about the user participation types in European housing regeneration projects, in-depth interviews and a questionnaire were used to understand the participation tendencies of the users in the Levent District.

\section{User participation in housing regeneration projects in European countries}

Existing modern housing estates are very important for sustainability, especially in terms of the cultural memory of cities. Few are listed and under protection, but most of them are struggling with spatial quality problems.

In European countries, there is a great deal of social housing units in the form of mass housing stock that was designed and constructed between the 1920s and the 1970s. Nowadays, these huge social housing complexes are in use, but over fifty years many things have changed: people, systems and life styles. So, users have now begun to try to satisfy today's needs with this stock. They need some changes in order to live in better conditions and in qualified, comfortable places. In this context, there have been some examples of implementations relating to regeneration, in order to create better quality living spaces with sustainable culture and economy. The users' initiatives, governmental offices, academics and national protocols, with the help of several funds and investments, generally developed these strategies.

Sustainability of the space quality in the urban environment relates to how to re-use the existing building stock. It can be provided by the countries' visions and public/users' consciousness of the modern housing stock. The main reason for the environmental quality problems is a lack of governmental policies or organisations on space quality [3]. The lack of detailed policies makes it difficult to develop systematic participatory programs on existing stock. For sustaining quality on whether to maintain existing stock or build new houses, some programs were developed to control the quality of the space in buildings. Today, energy efficiency is the main aim of the sustainability of quality programs. Passive House standards commonly used in Germany improve building quality. We can also talk about some energy certificates that are helping to improve housing quality, such as LEED and BREEAM.

The United Nations, UN-Habitat, European Program Urbact, WHO and the OECD have all examined the subject of environmental quality in sustainable development programs. Although developing common quality programs in Europe, each country has created its own program with the help of national policies [4]. With these programs, they aim to improve quality with participation, but they need to educate or organize some workshops with users to raise awareness $[5,6]$. Burton [7] pointed out that users should be encouraged to participate in these improvement projects. With this participation, users can voice their own ideas and demands. 
When we look at housing regeneration examples, it can be seen that the main common idea from the examples from Europe is that the projects were realized with user participation. Users explained their ideas to the authorized organisations and commissions. During the design and construction process, they also attended to the projects. In addition, urban policies encouraged user participation in the regeneration implementations. Some housing regeneration projects were based on these approaches in European countries.

In France, the people have been asked to insulate their houses since the 1980s. But regeneration examples are not only about insulation, they are also about all kinds of quality improvements [8].

Torre Bois-le-Prêtre project is one of the best examples in Paris. The building was constructed in 1960 as a social housing block. The first renovation was made in 1990, just for insulation. After many years, users were experiencing some problems with the spaces that related to acoustics, daylight and volume. Users asked the Paris Habitat organisation to renovate the houses. An architectural redesign competition was opened and Frédéric Druot, Anne Lacaton and Philippe Vassal redesigned the building in 2011. Regeneration seemed to be a better option than to totally demolish and re-build the social housing stock. In this process, users participated in the design. Architects prepared posters so that they could see the before and after designs of their houses (Figure 1). The design was finalised only after users had commented on the photos. Again, during the construction, users did not leave their homes. They had a chance to influence the design and construction processes [8].


Figure 1: Torre Bois-le-Prêtre, before and after.

After regeneration, users prepared a new contract with each other that set out the responsibilities of the users regarding the maintenance and sustainability of the spatial quality [9].

In Germany, there are some programs that have aimed to improve building quality, especially with regard to energy efficiency; social sustainability in these settlements is also important. Leinefelde Südstadt is a regeneration project that has been developed for the sustainability of communities (Figure 2).

Both environmental and social sustainability were to be provided by the governmental offices. The houses were built in a prefabricated system in the 1960 s, but the area lost its quality in the 1990s and the buildings became old and neglected. Residents started to leave the area and it became a kind of inert area. With the aim of re-adapting the settlement into the city life and improving quality, governmental offices set up a competition and Stefan Forster Architects prepared 
a regeneration project plan. During the design, surveys and interviews were undertaken with the users. After analysing the data, users' demands were transferred to the projects. While developing the regeneration project, visual projections, workshops and psychological awareness of the quality programs were undertaken [10].


Figure 2: Leinefelde Südstadt project: before and after.

Overall, a common goal of these projects was to foster user participation. Users were the most important actors in the regeneration process, from design to construction. Different actors with different characteristics and abilities participated in the regeneration processes. It has been recognized that users are the most effective actors when solving quality problems.

For regeneration projects that are on different scales, a different number of users' participation is required. It is important that this participation exists as a legal right in cities. User participation should be organized at national and international scales [11]. Not only can users contribute to the physical regenerations, they can also provide a more economically effective project [12]. The subject of user participation concerns all countries; it is an international issue. In the United States, the concept of participation has been used in new city design since the 1970s [13]. In 1992, the participation theme emphasized the importance of the partnership between local governmental organisations and users. Users should be organized not only in the decision-making stage, but should also be sustained in the entire process from design to construction. On one hand, participation increases the awareness of the citizen; on the other hand, it reminds them of the responsibility of the city and settlement to the users.

Non-governmental organisations play an important role in working with people to provide participation. At the settlement scale, neighbourhood societies are important to encourage people to work together [14]. When examining the projects, it is clear workshops and educational programs are helpful to increase awareness of society. Users of the city and region expect to be in the organisation throughout the process [15]. If the participation organisation is not created in a correct way, user satisfaction is badly affected [16]. 


\section{Tendencies of user participation in a housing regeneration project in İstanbul}

The case study is based on questionnaires and interviews that can be used to collect both quantitative and qualitative data and the Levent District has been selected for the case study area for this research. Literature and history research was undertaken to understand and evaluate the area. First, spatial quality problems in the area were examined with the observations on the site. Questionnaires and indepth interviews were conducted in the area, in accordance with the focus that has been chosen. The results of those questionnaires and interviews were used to analyse the ideas of people living in this place on participatory approaches and housing quality.

When the results of the questionnaires and in-depth interviews were examined, it was observed that the main spatial problems were related to the lack of regular maintenance regulated by laws, or the lack of consciousness about modern housing heritage. With the result of analysing the needs and ideas of residents, along with understanding their participatory approaches, this study aims to discuss and describe participation ideas on housing regeneration strategies.

\subsection{Levent neighbourhood}

Levent is one of the main business districts in Istanbul. It is located on the European side of the city and is the home to a number of Turkey's best-known office developments and skyscrapers. The Levent District is one of the first modern housing estates in Turkey (Figure 3). The construction of the houses was undertaken in four sections, starting in 1951 and completed in 1958.
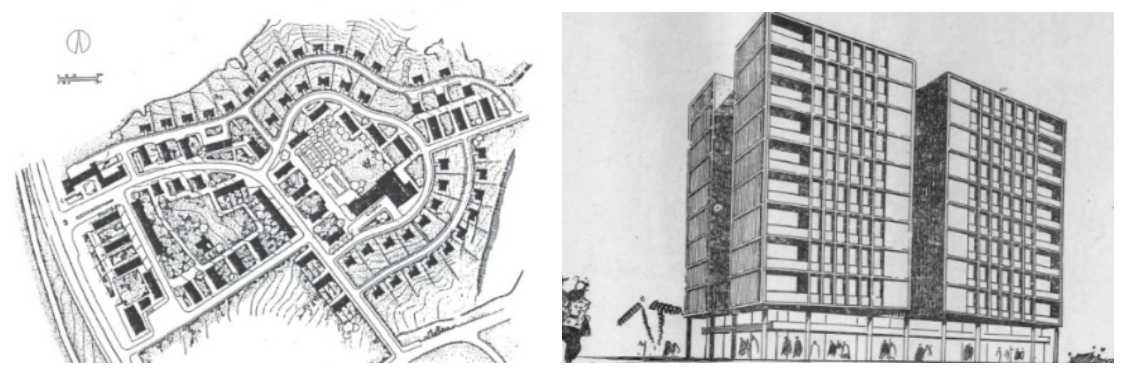

Figure 3: Levent District.

When the Levent District was designed, the area was used as a farm. Since 2000 , with the connection of highways, the area has become the most important district for trade and office buildings. There have been lots of skyscrapers built. As the District has developed, it has lost some of its original characteristics and has some quality problems.

Today, users are making a range of different modifications to their buildings/spaces; however, different individual modifications could damage the 
settlement's integrity in terms of design and space. The area needs a regeneration strategy with a participatory way to improve the quality of the buildings and the environment.

\subsection{In-depth interviews and questionnaires}

In-depth interviews and questionnaires were carried out to understand the participatory tendencies of the users. Spatial quality problems were determined during the observations on site. Some security requirements, technological needs (air conditioning) and extra closed room (volume) needs were also observed on the site.

After site observation, four users were chosen through which to understand the spatial quality problems and participation idea for improving quality in the area. Users were involved with in-depth interviews whereby they remarked on their actual needs. They talked about the necessity of regeneration approaches for improving quality. As they are renovating their houses with individual ideas and initiatives, different design and construction techniques will occur in the same area. This causes a decrease in the total quality of the neighbourhood, and it loses the unique characteristic and value of the site and its buildings.

During the in-depth interviews, users said that social synergy could make the decision-making process easier if the users acted together with the same aim. They criticized the lack of societal culture. They needed to create a systematic decisionmaking process. With the in-depth interviews, it was seen that the neighbourhood has a lot of spatial problems that need to be solved. The users are volunteers for participation on the program that will organize the regeneration.

After the in-depth interviews, a questionnaire was carried out with residents in the Levent District. The dwelling units have two main purpose of use: offices and flats. The questionnaire was undertaken with 40 house users and 52 office users. Participation ideas and behaviours were searched. User profile (age, gender, education), ownership details, duration of use/occupancy, membership of a neighbourhood society, awareness and consciousness of the users, sense of belonging, the tendency of leaving the neighbourhood and the idea of participation were investigated.

With this site research, it was aimed to define the relationship between users' characteristics and their tendencies and behaviours on participation. To understand their characteristics, research was made about their personal characteristics like age, gender and education. Furthermore, concerning ownership status, duration of use and the idea of leaving the neighbourhood were determined to learn about their feelings about the area. And the awareness and conciseness about cultural heritage and conception of spatial quality were investigated. With all of these questions, data was collected to clarify the characteristics of the users. After collecting data, these results were analysed to find answers to the following questions: what is the relationship between users and characteristics, is it important to understand the users' behaviours before developing a participative organisation? 


\subsubsection{User profile (age, gender and education)}

The questionnaire was conducted with 92 users in total: 40 were residents (house users), 52 were office users. While the women users' percentage was 52.5 percent, the office users' percentage was 42.5 percent. Of the residents, 40 percent were 65 years old and over, while the office users' ages were generally between 22-34 and 35-44 years old. 42.5 percent of house users had graduated from university, while 65.4 percent of office users had graduated from university. It was seen that the user profiles were different between office and house users: the residents were older than the office users.

In spatial quality studies, it is necessary to define user profiles in the area that will be regenerated with the participation of the users. Participation tools should be specified for each profile to reach a systematic organisation. Each user group needs different instruments to communicate easily and comfortably. Besides this, user profile classification (defining) helps to understand different ideas about spatial quality. Problems can be defined in detail and suggestions can be explained correctly if user profile characteristics are known.

\subsubsection{Ownership status}

Ownership status is a very important definitive factor to understand users' behaviour. It was seen that the owners' and tenants' tendencies and behaviour were not similar. 70 percent of the residents that responded to the questionnaires were owners of dwelling units, and office users accounted for 23.1 percent. Office users were mostly tenants showing that office users have the ability to leave the neighbourhood. So it can be said that the possibility of leaving the area is a problematic factor in participation requests (demands). Tenants generally feel that they will move from the neighbourhood one day so they cannot be given the same importance as owners. It affects the participation tendencies of the users.

\subsubsection{Duration of use/occupancy}

The duration of use/occupancy is as important as ownership status. If the period is too short or too long, it can affect the feeling of belonging. This was seen in the results, whereby the lengths of stay by the residents and office users were different. 47.5 percent of residents had been living in the neighbourhood for 31 years or more. Office users were most likely to have been using the buildings for between $0-5$ and 5-16 years. The analysis of the differences in the length of stay by users was helpful to understand users' profiles and their tendencies.

Furthermore, users that had been living there for many years were able to define spatial problems in the area. They had more experience than the office users to explain the changes in the neighbourhood. Knowing an area well is important for identifying the problems and proposing solutions within a participatory way. The time period is also important for community feeling. If the users stay for a long time in the same neighbourhood, they can get to know each other. Over time, they can get together in several decision-making organisations. Creating a community is important for correct user communication. Being and feeling part of a community helps users to define their problems on common grounds. 


\subsubsection{Membership of a neighbourhood society (NGO membership)}

It is necessary to understand the participation tendencies of the users by searching community consciousness. In the Levent neighbourhood, there is a society that brings users together in every decision or special organisational, activities, but it is not obligatory to be a member of the society. Members want to create a neighbourhood consciousness and feeling of belonging to the area. The existence of a non-governmental organisation such as this society in the area helps to organize any quality strategies on the buildings. It was seen that there was only one member among the total 92 users surveyed. It can be said that the society of the neighbourhood is not suitable for all users. There should be several NGOs in the neighbourhood because there are different users who have different ideas and behaviour.

\subsubsection{Awareness and consciousness of the users}

One of the most effective factors in a participative regeneration project is the awareness and consciousness of the users. If the users know and follow the actual news and agenda, they can understand and define the quality problems easily. It is all about awareness and consciousness of the neighbourhood (value and problems) that users are living in.

The area on which the research was carried out was the first neighbourhood designed by modern movement ideas in the 1950s. It is a kind of modern architectural heritage for Turkish urban history. The area was listed as an urban preservation area in 2008 due to this unique character.

This research aims to test consciousness and the degree of awareness by asking participants the following two questions: Do you know that the neighbourhood is an important modern architectural heritage? Are you aware of this information? In the results, 77.5 percent of the residents and office users replied yes to the question. They were aware that the buildings in the neighbourhood are a part of Turkish modern architectural heritage.

The other question concerns the actual news and urban decisions about the area. Users gave the following information about their news gathering behaviour. While 60 percent of the residents followed the news, 30.8 percent of the office users followed the actual activities on the site. It can be said that residents were more willing than the office users to claim the area.

\subsubsection{Sense of belonging to the neighbourhood}

One other factor is a sense of belonging to the place that users are living in. Galster [17] explained the sense of belonging to the neighbourhood as feeling as one of the others that lives in the area. This sense is also related to duration of use/occupancy. The people that had been living in the same area for longer could feel more connected to it [18]. The feeling of belonging is related to social relations and their sustainability, so it needs a community feeling in a neighbourhood. It increases with community feeling or good neighbourly relations [19].

The question regarding a sense of belonging was only asked of the residents in Levent. 87.5 percent of the residents replied that they felt as though they belonged to the neighbourhood. In the research, it was seen that another part (12.5 percent) of the residents was unstable. Understanding the sense of belonging factor is 
important in organizing regeneration projects. If people feel that they are a community, they can come together easily and can make decisions about their neighbourhood.

\subsubsection{The tendency to leave the neighbourhood}

The idea of leaving the neighbourhood is related to that of ownership status and a sense of belonging. If users cannot have suitable economic conditions, or do not like the area, they do not feel a member of the community. Increasing house prices can cause residents to leave the neighbourhood. If the users want to leave an area, it is expected that they would not want to participate in the project or activities in the neighbourhood. The question regarding leaving the neighbourhood was asked of both residents and office users. Over 80 percent of both residents and office users did not want to leave the area. This is also related to the ownership status of the users. According to the answers, the tenants mostly had the idea of leaving the neighbourhood. 75 percent of the tenants of the residents stated that they wanted to move to another place; while 100 percent of the tenants of the office users wanted to leave. In this situation, it is expected that the office users would be unwilling to participate in organisations. So, the function is a kind of decisive factor to understand participation tendencies in a housing settlement.

\subsubsection{Participatory tendencies of the users}

The questionnaires concluded with a question about the participatory idea: What do you think about the participatory approaches in the regeneration strategies for improving the quality of the space in your neighbourhood? According to the answers, while 90 percent of the residents wanted to participate in the regeneration organisations, 46.2 percent of the office users wanted to be in the organisations (Figure 4).

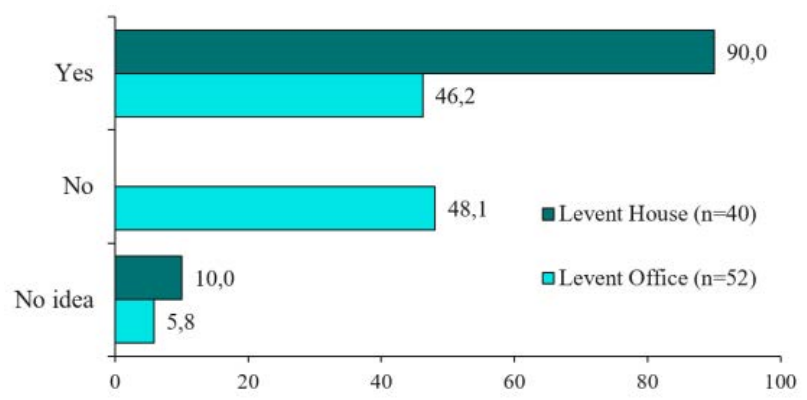

Figure 4: Participatory tendencies.

In detail, it was expected that there would be differentiations in the participation tendencies according to the ownership status. The owners of the houses wanted to participate 100 percent; 63.6 percent of tenants wanted to join regeneration organisations and 50 percent of office owners wanted to participate. In comparison with the residents, the office users' tendency was seen as weak as the owners were more willing to participate than the tenants. 


\section{Conclusions}

The buildings we see around us today make strong connections with the past. In this context, the housing stock that is from the past should be handled and kept alive, so these approaches provide spatial, social, cultural and economic sustainability. In Turkey, we often see the construction of new houses and the demolition of old ones as part of urban transformation projects, whereas regeneration projects should be developed for this modern housing settlement.

In Turkey, in the period between the 1930s and the 1970s, there were planned/designed housing estates with modern architectural visions. The buildings that were constructed in the early Republic of Turkey represent Turkish modernism, and they are historic documentaries. Nations need the buildings that are related to their past and memories. The housing settlements that are important for a city's memory should be reused and regenerated to sustain their value. The householders/dwellers need to be far-sighted for this strategic planning. These buildings' architectural value is very important for societies. It is useful to develop regeneration strategies and formulate participatory approaches for existing modern housing stocks. Actors who can influence the stocks in the process must be defined before the organisation. It is important to formalize planning the regeneration with different groups: local administrators, designers, city planners, dwellers, economists and other professionals. The involvement of various actors in a common platform can help to organize and manage the projects easier.

When the projects from European countries were examined, it was seen that there were several actors in design and construction processes. Unlike the users, actors gave the impetus to the regeneration with their awareness and consciousness about the stock and quality of space.

As the findings of the study points out that the most important actors are the users in the regeneration strategies. They can realize the spatial quality problems and can make decisions about their units. While formalizing participation type and defining the communication tools and instruments, we need to learn about the user profiles. User profile has the potential to define the strategy. Each user has different characteristics. Residents and office users' participation tendencies are different because the relations with their units (residence or office) are different. Office users give less importance than residents to their places; they feel that they are temporary in the neighbourhood.

Ownership status also affects the tendency for participation. Owners are the most important players in the program. Regulations should encourage them with funding or bank support so they may feel more willing to regenerate their houses. Owners' behaviours are more positive than that of tenants. Tenants must get permission from the owners of their dwellings, so they cannot feel free to make decisions about spatial quality. However, both owners and tenants are important source for learning about the problems on site as they can observe the spatial quality problems. This is not only for developing a regeneration strategy, but also for determining the problems; both users can provide useful information. Before starting regeneration implementation, it is important to create a team/group from the users to understand the problems. In order to improve the participatory group's 
consciousness and awareness, workshops and educational programs should be organized. A well-organized regeneration strategy cannot exist without user participation. From the very beginning, through to construction and management, the strategy needs users' ideas, stories and decisions about their places.

\section{References}

[1] Hall, P., Can cities be sustainable? The Human Face of the Urban Environment: Proceedings of the Second Annual World Bank Conference on Environmentally Sustainable Development, eds I. Serageldin, M.A. Cohen \& K.C. Sivaramakrishnan, The World Bank: Washington, DC, pp. 32-38, 1994.

[2] United Nations World Commission on Environment and Development (UN-WCED), Report of the World Commission on Environment and Development 1991: Our Common Future. www.un-documents.net/ourcommon-future.pdf.

[3] Meijer, F.M., Existing housing stock: How to improve the building quality? 4th Triennial International Conference, Rethinking and Revitalizing Construction Safety, Health, Environment and Quality, Construction Research Education and Training Enterprises: Washington DC, pp. 528543, 2005.

[4] Clemente, C. \& De Matteis, F., Housing for Europe, Strategies for quality in urban space, excellence in design, performance in building, 2010. www.urbact.eu/file/289/download?token=yzKftnS_.

[5] Benton, J.F., Survey on Architectural Policies in Europe. European Forum for Architectural Policies: Amadora, Portugal, 2012.

[6] McLennan, F.J., The Philosophy of Sustainable Design: The Future of Architecture, Ecotone LLC: Kansas City, MI, 2004.

[7] Burton, S., Handbook of Sustainable Refurbishment Housing, Earthscan: New York, 2012.

[8] Lacaton, A., Vassal, J.P. \& Druot, F., Plus: Large Scale Housing Development - An Exceptional Case, 2G Press: Barcelona, 2007.

[9] Ginelli, E. \& Castiglioni, L., Perché Valorizzare e Riqualificare il Patrimonio di Edilizia Residenziale Pubblico (Why enhance and upgrade the public housing assets). Techne, 4(1), pp. 45-50, 2012.

[10] Leinefelde Project, www.sfa.de.

[11] Darke, J., Architects and user requirements in public housing: 1. architects' assumptions about users. Environment and Planning B: Planning and Design, 11, pp. 389-404, 1984.

[12] Oakley, P., The concept of participation in development. Landscape and Urban Planning, 20(1-3), pp. 115-122, 1991.

[13] Sanoff, H., Community Participation Methods in Design and Planning, John Wiley: New York, pp. 1-36, 181-220, 2000.

[14] Harvey, D., Rebel Cities, From the Right to the City to the Urban Revolution, Verso: London, 2012.

[15] Faga, B., Designing Public Consensus, John Wiley: New Jersey, 2006. 
[16] Cabannes, Y., Personal Communication to EDAW. Designing Public Consensus, ed. B. Faga, John Wiley: New Jersey, 2004.

[17] Galster, G.C., On the nature of neighbourhood. Urban Studies, 38, pp. 2111-2124, 2001.

[18] Sampson, R.J., Local friendship ties and community attachment in mass society: A multilevel systemic model. American Sociological Review, 5, pp. 766-779, 1988.

[19] Van Gent, W.P.C., Estates of content: Regeneration and neighbourhood satisfaction. Mass Housing in Europe, Multiple Faces of Development, Change and Response, eds R. Rowlands, S. Musterd \& R. Van Kempen, Palgrave Macmillan: London, pp. 77-100, 2009. 